\title{
INTERVENCIONISMO ESTATAL E POLÍTICAS DE DESENVOLVIMENTO NA AMÉRICA LATINA ${ }^{1}$
}

\author{
Renato Boschi* \\ Flavio Gaitán ${ }^{* *}$
}

\begin{abstract}
Este trabalho analisa as dinâmicas dos países latino-americanos na última década, cuja característica distintiva é o enfraquecimento da hegemonia neoclássica e uma retomada de trajetórias de intervenção estatal na economia. A análise está centrada nos vetores constitutivos de uma agenda neo-desenvolvimentista e no papel que o Estado deve desempenhar na retomada do crescimento e do desenvolvimento sustentável. Focaliza-se o papel que o regime político e as instituições de governo cumprem no processo econômico, sugerindo-se que não haveria possibilidade de crescimento e desenvolvimento sem um Estado forte.

Diferentes trajetórias constituem a base a partir da qual operam um conjunto similar de intervenções delimitando um campo para a atação de novos governos, cujos instrumentos e margens de ação dependerão de um conjunto de características institucionais e de contexto que pautam a governabilidade e, em última análise, a natureza das políticas econômicas.

PALAVRAS-CHAVE: desenvolvimento, América Latina, instituições políticas, Estado, mercado.
\end{abstract}

"Se sabe, los períodos de transición duran una Jean Paul Fitoussi

\section{INTRODUÇÃO}

Este trabalho analisa as dinâmicas dos países latino-americanos na última década, na qual a característica distintiva é o enfraquecimento da hegemonia neoclássica e uma retomada de trajetórias de intervenção estatal na economia, observando-se uma diversidade de caminhos neodesenvolvimentistas. Nesse sentido, pretende representar uma contribuição à abundante bibliografia que foi produzida nos últimos anos sobre o papel do Estado e dos atores públicos e privados num processo de desenvolvimento.

* Professor Titular no programa de doutorado em Ciência Política IUPERJ/UCAM.

Rua da Matriz, 82 - Botafogo. Cep: 22.260-100. Rio de Janeiro - Brasil. rboschi@iuperj.br

* * Professor da Faculdade de Ciências Sociais da Universidade de Buenos Aires.

Rua da Matriz, 82 - Botafogo. Cep: 22.260-100. Rio de Janeiro - Brasil. flaviogaitan@gmail.com

${ }^{1}$ Escrito para apresentação no VI Encontro da Associação Brasileira de Ciência Política.
O progressivo enfraquecimento do neoliberalismo, como modalidade discursiva que respaldou a implementação das reformas setoriais no marco do ajuste estrutural, juntamente com uma reversão da deterioração dos termos de intercâmbio, sob a pressão da emergência das economias asiáticas (principalmente da China e da Índia), representam um marco propício para os países latino-americanos, cujo principal desafio consiste em quebrar um círculo vicioso e reverter as trajetórias prévias sinalizadas pelo subdesenvolvimento, pelo atraso relativo e pela desigualdade na distribuição de renda.

O eixo de análise está centrado nos vetores constitutivos de uma agenda neodesenvolvimentista e, especificamente, no papel que o Estado deve deempenhar na retomada do crescimento e no caminho do desenvolvimento sustentável. Analisase, particularmente, o papel do regime político e das instituições de governo em todo processo econômico. O pressuposto é claro: não há possibilidade de crescimento e desenvolvimento sem um Estado forte. Só o Estado, ancorado em um projeto desenvolvimentista em função dos interesses 
particulares nacionais e regionais, pode se constituir como regulador das assimetrias do mercado e como garantia das condições de inclusão social. Nesse sentido, o artigo se situa, dentro de uma perspectiva crítica, dentro da ampla literatura difundida nos últimos anos sobre as variedades de capitalismo (Amable, 2003; Boyer, 2005; Hall; Soskice, 2001; Huber, 2002; Menz, 2004; Schneider, 2004, 2008), que enfatiza, segundo distintas modalidades de coordenação, as diferenças nos regimes produtivos dos países desenvolvidos em termos de complementaridades que se estabelecem no plano da atuação das empresas, mas que, em termos gerais, tende a relegar o papel cumprido pelo aparato estatal (Schneider, 2007, 2008). Determo-nos no papel do Estado significa entender que ele se constitui como um fator de ruptura das possíveis complementaridades negativas, derivadas das trajetórias mais centradas no mercado, que predominaram até as crises finais do século $\mathrm{XX}$, abrindo espaço para um novo ciclo de desenvolvimento, especialmente para alguns países da periferia, como são os latino-americanos. Dito de outro modo: além de se constituírem como marco institucional dentro do qual as empresas atuam, as instituições estatais representam uma dimensão constitutiva do regime produtivo, aspecto que as análises mais recentes da abordagem das variedades de capitalismo estão tratando de reconsiderar (Hall, 2008).

O neodesenvolvimentismo é definido aqui como um modelo ainda em formação, que postula a construção de um espaço de coordenação entre as esferas públicas e privadas, com o objetivo de aumentar a renda nacional e os parâmetros de bem estar social. Apesar do peso que o fenômeno definido como globalização adquire nas economias da periferia, assumimos que os processos de desenvolvimento "continuam se apoiando na capacidade de cada país de participar na criação e difusão de conhecimentos e tecnologias e de incorporá-los no conjunto da atividade econômica e das relações sociais" (Ferrer, 2006). Isto é, que as asimetrias são explicadas fundamentalmente por fatores endógenos, mesmo que os espaços nacionais se constituam como sistemas abertos, em constante processo de adaptação, inclusive frente aos determinantes exógenos que surgem das características do sistema internacional globalizado. Nesse sentido, num excelente trabalho, Becker (2007) elabora uma crítica à noção de complementaridade, introduzindo o conceito de "abertura sistêmica" e "contestação a quadros de referência", para dar conta do processo de mudança orientado para a busca de competitividade das economias políticas no cenário internacional.

A trajetória dos países latino-americanos, nos últimos anos, mostra que os projetos nacionais para transitar no caminho do desenvolvimento, mesmo quando coincidem em reivindicar a neccessidade de modelos com um papel protagonista do Estado, são divergentes em relação às modalidades de desenvolvimento. Para além das diferenças nacionais, uma análise global das particularidades dos países da região é pertinente, porque todos, mesmo com suas especificidades, mostram uma maior presença do Estado na regulação da arena econômica. Em certo sentido, pode-se falar de uma dimensão geográfica das dinâmicas políticas e econômicas. As dinâmicas de democratização, de implementação dos processos de ajuste estrutural e de virada ideológica na orientação dos governos em direção a concepções antineoliberais têm sido contemporâneas, apesar da disparidade de ritmo e intensidade.

O trabalho se baseia na análise das tendências recentes na região, mas considera processos que são afetados, nesse sentido, pela dimensão temporal longo prazo. Na medida em que os legados dos diferentes países atuam como fortes condicionantes das opções possíveis em matéria de desenvolvimento econômico-social, deve-se ter em conta que se trata de processos sensíveis em longo prazo, devendo-se prestar atenção às transformações de larga escala. Tanto a questão da primazia do Estado como a dimensão temporal dos processos de desenvolvimento (Pierson, 2004) devem constituir pontos nodais nas análises acadêmicas, em que pese ser o primeiro tratamento do regime produtivo como epifenômeno e o se- 
gundo em termos dos equilíbrios que geram trajetórias dependentes mais ou menos estáveis e orientadas para a eficiência econômica, no marco da competitividade.

O artigo está dividido em três seções centrais. Em primeiro lugar, apresentamos o debate sobre as novas modalidades de intervenção estatal na órbita econômica. Em seguida, centramo-nos na análise das instituições e nos processos de realização das reformas necessárias para implementar um ciclo sustentável de desenvolvimento. Na parte seguinte, apresentamos certos indicadores que identificamos como o núcleo constitutivo da agenda neodesenvolvimentista na atual conjuntura, na América Latina.

\section{NEOINTERVENCIONISMO ESTATAL: a política volta à cena}

O declive do projto neoliberal, que reduziu o Estado a um papel passivo nas políticas desenvolvimentistas, legitimador das necesidades do mercado, representou um ponto de inflexão na emergência dos atuais processos de desenvolvimento e na orientação das práticas intervencionistas. Apesar da permanência do debate entre os defensores de maiores graus de intervenção do Estado na economia e aqueles que adotam postulados neoclássicos, o certo é que parece existir uma espécie de consenso sobre a necessidade de contar com maiores níveis de regulação da atividade econômica. As experiencias dos países latino-americanos, nos últimos anos, nas quais partidos ou coligações identificados como ideológicamente progresistas ou de contro-esquerda ${ }^{2}$ chegaram ao poder, dão conta de que, mesmo sem configurar um modelo férreo e homogêneo, quando se observam particularidades entre os diversos estados, eles apresentam como característica distintiva a defesa

${ }^{2}$ Dos presidentes em exercício, apenas Alvaro Uribe não é refratário a se identificar como parte do coletivo identificado como direita ou centro-direita. Os demais mandatários (Lula, Bachelet, Tabaré Vazquez, Morales, Correa, Chavez), ou os mais difusos (Kirchner, Garcia) reivindicam para si uma identidade de esquerda, social-democrata ou progressista. da intervenção ativa do Estado na órbita econômica e a necessidade de incluir o conteúdo e a orientação das políticas públicas nas necessidades de cada Estado-nação.

O neodesenvolvimentismo, com quebras e continuidades nodais a respeito do desenvolvimentismo estruturalista cepalino (Boschi; Gaitan, 2008), representa uma resposta à crise do estado neoliberal, e, ao mesmo tempo, uma posição particular frente às dinâmicas recentes do modo de produção capitalista. Nesse sentido, mais do que a variedade de respostas, a bibliografia recente (Rodrik, 2004; Stiglitz, 1998) reconhece a relação positiva entre intervencionismo estatal e êxitos nos modelos de desenvolvimento, além da impossibilidade de importar modelos econômicos sem tomar em consideração as particularidades locais. Frente à visão neoclássica, essa vertente da literatura nega as virtudes da primazia do mercado e destaca, por oposição, a noção de modalidades de intervencionismo estatal, na qual a avaliação de desempenho não seria medida por critérios de eficiência, senão, num sentido mais amplo, pela difusão de vantagens institucionais comparativas.

A relação entre Estado e mercado, entre política e atores econômicos, assume características particulares em cada momento histórico. Olugar comum sobre o projeto neoliberal se refere a uma "deserção" do Estado. Na realidade, ele cumpriu um papel muito mais ativo do que apenas ter se desligado da função de inclusão social e de regulação das esferas econômicas. Os anúncios de privatizações, de desregulação e descentralização das funções asumidas pelos Estados latino-americanos, durante grande parte do século XX, foram levados a cabo pelas frações dominantes, em função de sua autoridade soberana. Para além da visão difundida pelas análises econômicas neoclássicas, de que as privatizações constituiriam o desmonte e a redução do aparato estatal, com o objetivo de coibir o rent-seeking, e pelas análises políticas, na perspectiva da escolha racional sobre a necessidade de autonomização do Estado e o isolamento burocrático, a fim de reduzir pontos de veto e impor decisões, observou-se a formação de 
coalisões interessadas na construçãouma uma nova institucionalidade regulatória - um novo projeto de Estado - para garantir os benefícios das privatizações em longo prazo (Schamis, 2002).

Observa-se, assim, um grande paradoxo, que é um crescente intervencionismo estatal para renunciar a suas históricas tarefas, com a produção de um amplo espectro de leis e regulações para ampliar os espaços de autonomia do mercado, na crença de que o receituário do Consenso de Washington levaria os países da região a superar o histórico atraso. Além de um papel central do mercado, prevalecia uma visão tecnocrática de desenvolvimento. $\mathrm{O}$ denominado desmantelamento do Estado desenvolvimentista, fundamentalmente a partir de processos de privatizações, abriu espaços para uma nova coalisão vencedora, que antecipava ganhos futuros, moldando um novo aparato estatal e novas modalidades de intervencionismo regulatório com esse fim (Schamis, 2002).

Na atualidade, o papel intervencionista que o Estado assume apresenta características radicalmente opostas, e se proclama a necessidade de regular a economia, submetendo o funcionamento dos mercados (financeiros e produtivos) à lógica política. Nesse sentido, as possibilidades de transitar por caminhos de desenvolvimento sustentável se encontram limitadas por trajetórias prévias dos países latinoamericanos, observando-se maiores graus de liberdade naqueles países em que o ajuste estrutural de cunho neoliberal avançou menos (Brasil e Uruguai), ou onde, para além da lógica de centralidade do mercado, o Estado conservou elementos de coordenação econômica (Chile). Trata-se, aqui, de pensar, para esses casos, em termos de continuidade de trajetórias e adaptações progressivas como processo de mudança institucional, tal como se sugere no mencionado artigo de Becker (2007).

O debate em torno do pepel do Estado como componente e característica constitutiva de algunas modalidades de regimes produtivos é muito mais relevante no caso dos países da América Latina, para os quais não só importa o legado de cunho estatal desenvolvimentista, mas também o papel estratégico que o Estado assume na nova conjun- tura, no sentido de superar os fatores de atraso econômico que perduram e se expressam nas extremas desigualdades estruturais e sociais no interior de cada país e entre os diferentes países, em diversos graus. Mesmo que a preferência de distintas coalizões políticas possa ter expressado preferências variáveis ao longo do tempo, como, por exemplo, o crescimento sem distribuição, ou o seu contrário, a prioridade do emprego ou de políticas sociais de combate à pobreza, tais desigualdades estruturais são também uma dimensão constitutiva que marcam distintivamente as configurações do capitalismo na região.

Porém o novo tipo de intervencionismo estatal adquire particularidade em relação ao do passado. Em primeiro lugar, o Estado não se postula como interventor direto na órbita da produção. Para além da interferência dos aparatos estatais em certos enclaves considerados essenciais ${ }^{3}$ (o Petróleo no Brasil, Equador e Venezuela; o cobre no Chile; o gás na Bolívia), o certo é que o intervencionismo referese mais a uma modalidade híbrida de coordenação econômica ou de recriação de híbridos existentes (Becker, 2007, p. 277), do que a um retorno do Estado produtivo. Os esquemas de produção que subsistem não ocupam um papel central nas atuais dinâmicas. A geração de vantagens comparativas parece provir, na realidade, do financiamento de atividades produtivas, da capacidade de criar núcleos de especialização com altos níveis de eficiência e competitividade, da efetiva realização de processos redistributivos para reverter a pobreza e a desigualdade histórica, de modo que se resolvam as tensões entre trabalho e capital nas diversas estratégias redistributivas e da capacidade de os estados latino-americanos implementarem projetos consensuados de modo permanente, no tempo.

O Estado, por meio das diversas instituições, tanto aquelas que se localizam no cume do nível de hierarquia, como aquelas que constituem

\footnotetext{
${ }^{3}$ Essa é uma vantagem adicional dos países em que o projeto neoliberal apresentou um menor grau de avanço. $\mathrm{O}$ controle dos recursos energéticos no Brasil, Equador (onde o petróleo representa 35\% do ornamento público), Bolívia e Venezuela, ou do cobre no Chile representa uma claram vantagem em relação à Argentina, que privatizou o petróleo e suas empresas de energia.
} 
seu aparato administrativo, aparece como o único ator capaz de reverter as externalidades negativas. As experiências passadas e as mudanças operadas no modo de produção capitalista em âmbito global impedem, de fato, uma volta a modelos desenvolvimentistas clássicos. Nesse sentido, existem dois grandes vetores, no plano da economia, por um lado, e da política, por outro, que constituem parte das condições de possibilidade de reverter as trajetórias prévias dos diversos países da região: o fator político e o estritamente econômico.

Por um lado, encontramos aquelas variáveis políticas que são centrais na geração de modelos desenvolvimentistas inclusivos e sustentáveis. Frequentemente deixada de lado nas análises sobre a temática, deve-se voltar a incorporar a conflitiva relação que se costuma estabelecer entre política e desenvolvimento socioeconômico. Em princípio, para além de todo o corpus teóricoprogramático, a aplicação dos projetos de desenvolvimento que se dá no âmbito das unidades nacionais implica, para ter êxito, um conjunto de leis, regulamentações e uma série de aparatos administrativos com a capacidade e o poder de fazêlas cumprir.

O papel das instituições adquire uma importância central. Nas palavras de Amable, “... as instituições desempenham um papel na economia, não para se isolar umas das outras, senão para combinar-se; pode-se conceber os 'modelos nacionais' como uma combinação particular de instituições complementares”, ou, nas palavras de Becker (2007, p. 278), "configurações institucionais que ganharão certo nível de sistemicidade por processos societais de ensaio e erro.”

Certas características da ação estatal introduzidas na análise pela teoria da Regulação aparecem como nodais. Por um lado, a complementaridade define a situação em que os arranjos institucionais, nos diferentes espaços, são influenciados, limitados ou reforçados na sua ação pelos diferentes acordos institucionais postos em prática em outros âmbitos. Um exemplo clássico, que adquire uma grande importância na geração de bem estar para os assalariados, é o reflexo que os acordos institucionais do mercado de trabalho podem gerar, por meio das negociações entre os diversos atores envolvidos, no desdobramento de estratégias de qualificação da mão de obra. A existência de acordos mais ou menos estáveis e de relações contínuas e próximas entre empresas produtivas e financeiras possibilita relações mais estáveis, que se expressam, por sua vez, em maiores níveis de estabilidade no emprego para o conjunto das empresas (Amable; Barre; Boyer, 1997).

A hierarquia, por sua vez, se refere às restrições e motivações que uma instituição encontra e deve-se levar em consideração a influência que o desdobramento de outras instituições exerce sobre ela. Significa que a reforma de certo arranjo institucional dado pode gerar uma transformação nos outros acordos, desencadeando uma situação de questionamento das complementaridades constitutivas de uma determinada configuração institucional, por meio da qual se impõem transformações ou modificações nas instituições, em sua totalidade.

A naturaza da coalizão política é parte de um eixo mais amplo, que inclui não só atores que se encontram conjunturalmente no governo, mas também as características do sistema político (pluralismo, fragmentação, divisão de poderes, etc.). Destaca-se, aqui, uma dimensão relativa à governabilidade, em termos das coalizões que chegam ao poder e buscam implementar uma plataforma mais desenvolvimentista. A situação, nesse plano, é bastante diferente em cada contexto nacional, o que chama a atenção para a importância dos fatores político-institucionais na configuração dos regimes produtivos, o que geralmente pode fazer diferença do ponto de vista do desempenho econômico.

A existência de pontos de inflexão e, conseqüentemente, de novos pontos de equilíbrio desejáveis dependeria das coalizões de apoio a uma plataforma desenvolvimentista pós-neoliberal. A maior ou menor capacidade que os sistems políticos mostram para gerar consensos em torno de certo núcleo mínimo é uma característica central em todo modelo de desenvolvimento. Partimos da 
consideração do desenvolvimento como um projeto nacional, que deve contar com a participação dos diversos atores sociais (empresários, trabalhadores, políticos, técnicos do governo). Nesse sentido, trata-se de recuperar a idéia de projeto nacional, agregando também a dimensão regional.

Assim como a bibliografia resgata, analisando as experiencias históricas, que não se observam casos de desenvolvimento sem papel ativo do Estado (Stiglitz, 1997; Rodrik, 2005), nenhum país se desenvolveu sem um projeto claro de expressão de sentimento de nação (Sicsu, 2005). OGrowth Report (2008), elaborado pela Comissão sobre Crescimento e Desenvolvimento, delineia a existência de um novo consenso que, apesar de continuar atentando para o valor da estabilidade macroeconômica e para o objetivo de conseguir altas taxas de poupança e investimento por meio de mercados competitivos e dinâmicos, desloca o eixo da orientação do desenvolvimento nacional do mercado para o Estado. Desse modo, em detrimento da privatização de empresas e do livre mercado, pilares do Consenso de Washington, o Informe destaca a centralidade do Estado desenvolvimentista na geração das condições para o desenvolvimento, incluindo altas taxas de investimento em infra-estrutura, educação, ciência e tecnologia, além de gasto público social.

A geração de um projeto de desenvolvimento, assim entendido, traz para o sistema político um componente-chave na canalização de demandas. Esse ponto adquire maior centralidade porquanto todo acordo programático, entendido em longo prazo, pode dar lugar a reacomodações na estratificação social, gerando retrocessos e férreas oposições, ou seja, réplicas ao quadro de referência da variedade de capitalismo em questão. A maior ou menor capacidade do sistema político para enfrentar situações de conflito parece constituir uma variável central (Faletto, 1996; Becker, 2007). As diversas políticas que se busca levar à prática mobilizam atores e interesses que enfrentam um jogo de estratégias, numa dinâmica que, por natureza, é incerta. As instituições, em uma democracia pluralista, têm um papel-chave no processo de entendimento e de criação de pontes entre alternativas opostas, com o objetivo de evitar que a arena política se converta em um cenário de um jogo soma zero.

Nesse sentido, os atores políticos e o jogo que se estabelece na canalização e mediação das demandas assumem um papel-chave em nossa perspectiva, na qual estabelecemos que as condições de possibilidade de estratégias de desenvolvimento se vinculam com a construção de um projeto nacional, sem que necessariamente isso signifique nacionalismo, em seu sentido clássico. Na realidade, "nacional" se refere, em primeiro lugar, a um projeto que conte com o consenso de atores representativos e, por outro lado, que renuncie às políticas impostas por organismos multilaterais ou países centrais e formule caminhos nacionais de desenvolvimento. Pode-se afirmar que os países que menos avançaram nas reformas estruturais são aqueles que conservaram maiores graus de liberdade para implementar uma agenda neodesenvolvimentista e que foram relutantes em copiar modelos como uma doutrina ecumênica, seguindo caminhos próprios. O mesmo se pode dizer das diferenças nacionais para reverter a crise de crescimento, ou para dar o salto nos níveis nacionais de desenvolvimento, de certos países asiáticos como a China (que está levando a cabo sua própria transição para o capitalismo) ou a Malásia. ${ }^{4}$ Também Taiwan e Coréia do Sul que, por iniciativa do modelo japonês do pós-guerra, representaram, nos anos 70, casos exitosos de industrialização, basearam-se em estrratégias estatais de incentivos seletivos de certos objetivos considerados centrais para os projetos nacionais. Essas experiências demonstrariam: i) a importância dos caminhos autônomos, com renúncia à implementação das reformas "de manual”; ii) o papel-chave que o componente político e os funcionários técnicos podem exercer nos caminhos a seguir em função de um determinado projeto nacional e iii) a centralidade dos mecanismos de coordenação e canalização de interesses. De fato, certos estudos, entre os quais se destaca

${ }^{4}$ Como assinalam Rodrik e Kaplan (2002), a Malásia enfrentou a crise asiática com receitas alternativas às propostas pelos organismos internacionais de crédito e conseguiu melhores taxas de recuperação em um menor lapso de tempo do que aqueles que aderiram ao manual da comunidade internacional. 
Evans (2005), apresentam a emergência dos denominados tigres asiáticos, que são casos de catch up bem sucedidos, com uma dinâmica para a qual convergem a capacidade das burocracias para criar elites orientadas para o mercado, ao mesmo tempo dos mercados para estabelecerem uma inter-relação com as burocracias estatais, escapando-se a processos do passado, como a predação e o militarismo.

As mudanças no sistema transnacional que os especialistas qualificam como multipolar, ou, numa perspectiva extrema, como de carente de polaridade, possibilitariam maiores graus de liberdade na geração de possibilidades para a modificação do mapa de atores globais, especialmente nas margens do sistema global. Assim, certos países situados na semi-priferia, nos termos de Wallerstein (2001), teriam maiores possibilidades de provocar alguma mudança no sistema transnacional. ${ }^{5}$ É uma oportunidade para contestar uma visão centralista a respeito do funcionamento do modo de produção capitalista e afirmar que é possível um desenvolvimento capitalista na periferia, com caminhos próprios, e que um discurso da globalização como espaço que supõe um caminho único de desenvolvimento constitui uma falácia.

Uma característica claramente distintiva do atual ciclo intervencionista é a defesa irrestrita da democracia como regime político. Se, no passado, a modernização era um discurso proclamado também por segmentos castrenses, imprimindo, nos diversos golpes, iniciativas de cunho nacionaldesenvolvimentista, na atualidade não se põe em dúvida que os mecanismos democráticos são vistos como "the only game in town" (Linz, 1991). Essa situação gera maiores espaços para a política. Mesmo quando, no atual ciclo democrático, se contam 14 experiências de presidentes ${ }^{6}$ que não conseguiram concluir seus mandatos (Hagopian; Mainwaring,

${ }^{5}$ O protagonismo do G20, nas negociações da Rodada de Doha, as demandas cada vez mais ressonantes de Países como Brasi, México ou Índia, na modificação dos estatutos dos organismos Multilaterais de Crédito ou co Conselho de Segurança das Nações Unidas, ou as declarações de líderes de países centrais a favor do ingresso do Brasil ou Índia no G8 parecem confirmar essas possibilidades. Do mesmo modo que a existência de uma sigla cada vez mais utilizada (BRIC), para se referir a Brasil, Rússia, Índia e China como economias que disputarão lideranças num futuro próximo.
2005), a novidade em relação a um passsado não tão remoto é que as crises, mesmo aquelas mergulhadas em conflitos sociais, como no Equador ou na Argentina, foram solucionadas no marco das instituições democráticas de governo. Reforça-se, desse modo, a necessidade de aprofundar a discussão acadêmica sobre o papel das instituições na superação das crises e, mais ainda, de focalizar estratégias de desenvolvimento no veio de trabalhos da escola institucionalista. Nesse sentido, são centrais os trabalhos de North (1991), que delinearam a íntima relação entre economia e política, argumentando, inclusive, que não há possibilidade de se explicar o desempenho das sociedades sem levar em conta a relação entre ambas as esferas.

Entre as instituições, adquirem centralidade os sistemas partidários que constituem a plataforma de mediação e procesamento do conflito entre diversos interesses, numa perspectiva pluralista. Nesse sentido, a evolução para dinâmicas que revertam a tendência histórica a negar a legitimidade dos competidores no jogo eleitoral aparece como requisito central. Não se trata apenas de obter maiores níveis de transparência política e de modernizar os processos de seleção de candidaturas e de divisão de lugares nas legislaturas, mas de avançar numa dinâmica institucional para sistemas que melhorem a representação política, com o objetivo já mencionado de estabelecer acordos macro baseados numa simples participação cidadã e setorial. Dito de outro modo: trata-se de ampliar a participação e os intercâmbios entre os diversos atores. Na medida em que um projeto desenvolvimentista implique a participação de maior quantidade de atores representativos do âmbito político, empresarial e de organizações não governamentais, haverá maiores possibilidades de que tal proposta seja vista como própria pelos envolvidos nas dinâmicas que possibilitam o avanço e pelo conjunto da sociedade.

${ }^{6}$ Fernando de la Rúa, Argentina (2001); Fernando Collor de Mello, Brasil (1992); Hernán Siles Suazo (1985), Gonzalo Sánchez de Lozada (2003) e Carlos Mesa (2005), Bolivia; Abdalá Bucarán (1997), Jamil Mahuad (1999) e Lucio Gutiérrez (2005), Equador; Jorge Serrano Elías, Guatemala (1993); Jean-Bertrand Aristide, Haiti (2004); Raúl Cubas Grau, Paraguai (1999); Alberto Fujimori, Peru (2000); Joaquín Balaguer, República Dominicana (1994), e Carlos Andrés Pérez, Venezuela (1993). 
Nesse particular, observam-se, na América Latina, diferenças notáveis entre as diferentes realidades que abarcam desde sistemas relativamente estáveis, até experiências que negam toda a legitimidade às coalizões de governo. Entre as diferenças, se encontram o tipo de sistemas partidários, a quantidade e a qualidade dos atores intervenientes no jogo político e o papel das instituições na mediação de interesses, entre outras.

De um lado, encontra-se um grupo constituído por Equador, Venezuela e Bolívia, ${ }^{7}$ em que a característica mais saliente é a clara dificuldade de canalizar os conflitos por meio de instituições polí ticas. Observa-se, em princípio, uma negação da legitimidade dos presidentes em exercício, somada a uma impossibilidade de formar um eixo opositor coerente, estável e com chances de constituir-se em opção certa de governo. Os atores não políticos costumam permanecer inseridos numa dinâmica de jogo de resultado nulo, em que a representação de interesses assume perfis particulares.

Desde o início de seu governo, em 1999, Hugo Chávez enfrentou uma oposição sem disposição de estender pontes de legitimação de seu exercício. De fato, a constante tem sido a falta de comunicação e o ataque centrado no suposto "militarismo" e no "caráter autoritário" do presidente Chávez, que pode ser considerado um produto do ocaso da antiga hegemonia acordista de COPEI e da Ação Democrática, e baseou seu governo, mais do que no acionar das instituições políticas, em uma comunicação direta com o povo e no respaldo popular de setores excluídos. O desencadear de estratégias tendentes a recuperar espaços de poder por parte da oposição, como a renúncia dos candidatos dos partidos outrora majoritários em favor de Enrique Salas Romer, ${ }^{8}$ como candidato

${ }^{7}$ Em princípio, esses países connstituiriam um eixo que reivindica, ao menos no plano discursivo, alternativas de tipo socialista para seus governos e que se expressa na constituição da ALBA, da qual o Equador renunciou a participar,e ficou finalmente integrado por Bolívia, Cuba, Dominica, Nicarágua e Venezuela.

${ }^{8}$ Apesar da posição dos partidos tradicionais, Chavez obtuve $56,20 \%$ fente a $39,97 \%$ do candidato do projeto Venezuela, qua contaria, apenas dias antes do ato eleitoral, com o apoio de COPEI e Ação Democrática. A diferença foi de mais de um milhão de votos. do Pólo Democrático, que se constituiu num espaço que aglutinou as formações políticas tradicionais, não resultou eficaz. Tampouco foram úteis as denuncias de fraude e manipulação eleitoral que foram efetivadas por observadores eleitorais como a OEA e o Centro Carter. Para além dos altos e baixos nos resultados eleitorais, é inegável o respaldo eleitoral da cidadania à coalizão governante que foi vencedora em três eleições presidenciais. ${ }^{9}$

A radicalização do conflito foi crescente. No segundo mandato do presidente Chávez, recrudesceram os embates da oposição, especialmente desde a promoção do Decreto Habilitante. FEDECAMARAS y la CTV (Confederação de trabalhadores da Venezuela) foram atores centrais na manifestação contra esse pacote de medidas. O protagonismo da central empresarial, na dinâmica política que se dá entre governo e oposição nesse país é tão profundo que, no marco da intenção de golpe de estado contra Chavez, o presidente de FEDECAMARAS, Pedro Carmona, chegou a jurar como presidente interino, anulando as leis habilitantes e dissolvendo o Parlamento, o Tribunal Supremo de Justiça e a Defensoria do Povo. Em 2005, toda a oposição renunciou a apresentar candidatos às eleições legislativas, razão pela qual todas as cadeiras foram para a situação.

Na Bolívia, Morales não só enfrenta permanentes embates da oposição, que invoca um suposto espírito autoritário mas, de modo perigoso, tem sofrido, até o momento, derrotas em quatro plebiscitos autonomistas que tiveram lugar em Tarija, Santa Cruz, Pando e Beni, iniciativas que, além de terem sido qualificadas de inconstitucionais e separatistas pelo presidente, feriam a autoridade presidencial. ${ }^{10} \mathrm{O}$ estopim foi a redação de uma nova constituição, rechaçada pelas zonas mais acomodadas

\footnotetext{
Demais, Numa clara intenção de legitimar sua condição, venceu no referendo sobre a continuidade do presidente Chávez, realizado em agosto de 2004, com o aval de transparência da OEA e do centro Carter, obtendo 59,1\% dos votos.

${ }^{10}$ As consultas convocadas pelos prefeitos de Beni, Ernesto Suárez; de Pando, Leopoldo Fernández; de Tarija, Mario Cossío e de Santa Cruz, Rubén Costas foram realizadas, para além das intenções de diversas organizações, entre elas a Igreja Católica, para consensuar posições. A Corte Nacional Eleitoral (CNE) considerou-as ilegais.
} 
do país, por seu suposto ataque às autonomias regionais. A chamada a um referendo revocatório do presidente Evo Morales e de seu vice-presidente Álvaro Garcia Rivero, convocado para o dia 10 de agosto, não resultou em maiores níveis de institucionalização da crise. Pelo contrário, não só persistem as diferenças entre governo e oposição, mas acresce que essa se dividiu entre aqueles que aceitam a chamada revocatória e aqueles que se negam a participar.

O Presidente Correa é, em grande parte, expressão da profunda crise político-econômica de que padece o Equador e que culminou, inclusive, com a dolarização de sua economia. De fato, assumiu a presidência a partir de uma campanha que anunciava a "disfunção da partidocracia tradicional”. A oposição do PRIAN (Partido Renovador Institucional Ação Nacional) e do PSC (Partido Nacional Cristão) contaram com o financiamento empresarial. A Aliança País (Pátria Altiva e Soberana), Partido Socialista e Frente Ampla, enumerou, ja quando da sua campanha, uma série de eixos que implicavam uma ruptura com o passado, enfrentando o poder mafioso da partidocracia. Em menos de um ano, Rafael Correa se submeteu a quatro eleições: os dois turnos das eleições presidenciais de 2006, o referendo respaldatório do chamado à Assembléia Constituinte, em abril de 2007, e a eleição dos membros da Assembléia Constituinte, de 30 de setembro de 2007.
Um segundo conjunto de países, entre os quais se poderiam incluir Uruguai, Chile, Brasil e Colômbia, combina um sistema partidário que apresenta alternância no exercício do poder e um papel ativo do Parlamento. No Chile, o objetivo de superação do regime autoritário de Pinochet tornou possível a constituição de uma coalizão mais homogênea, orientada para o centro, que se revelou pragmática e bastante eficiente na construção de um projeto de país. Essa coalizão foi denominada como regime normativo, como referência a que partidos políticos de distinta procedência ideológica põem em prática políticas públicas homogêneas. Em parte, essa situação se explica porque a discussão, excluídos os partidos radicais (fundamentalmente o PC) do parlamento, se dá como um pêndulo, entre o centro e a direita. Contudo, a partir do governo de Ricardo Lagos (2000-2006), sob a liderança do Partido Socialista, a permanência e a estabilidade da coalizão têm enfrentado, de modo cada vez mais freqüente, uma série de obstáculos e oposições articuladas de diversos atores que se apresentam como um um elemento de pressão para a adoção de políticas públicas mais progressistas, dando lugar a maiores níveis de conflito social, que parecem marcar a presidência da atual presidente, Michel Bachelet. ${ }^{11}$

No Brasil, o presidente Lula e a elite do governo devem lidar com o pragmatismo de uns e o dogmatismo de outros, o que acaba por dificultar par-

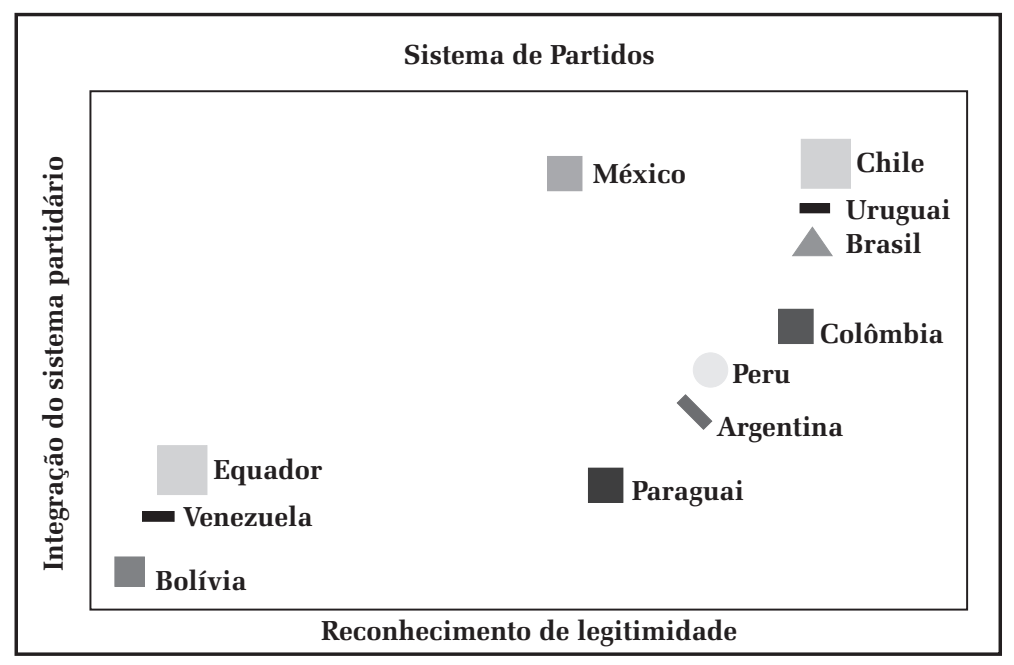

${ }^{11}$ Certas clivagens dividiram as águas nos partidos membros do Pacto, como a renovação da lei de contratos de trabalho e o aumento das contribuições. Por sua vez, a greve de estudantes (que alcançou quese $80 \%$ deles) pôs em xeque a estabilidade e a imagem positiva do gobernó (a imagem caiu de 60 a $44 \%$ de aceitação, o percentual mais baixo até agora obtido por um presidente da convenção). Ademais houve uma crise de mudanza de ministros, da Economia, Interior, Fomento e Reonstrução, e Interior. Outros problemas aconteceram em torno da crise energética e o uso de recursos adicionais gerados pela elevação do preço do cobre. 
ticularmente a tarefa de definir e obter apoio para um projeto de mais longo prazo que consiga situar o país commais eficácianocaminhododesenvolvimentismo. Essa heterogeneidade das coalizões governamentais, no Brasil, não é exclusiva do atual período, sob a liderança do Partido dos Trabalhadores. Para viabilizar sua agenda de reformas liberais no âmbito doméstico (privatização de serviços públicos, interrupção de monopólios estatais, entre outras medidas), o governo de Fernando Henrique Cardoso se apoiou numa base heterogênea de partidos, obtendo, em seus dois primeiros anos, uma série de vitórias nessas áreas.

O Uruguai é realmente um caso interessante. A lenta construção do Encontro Progressista Frente Ampla, que culminou com a chegada à presidência do ex-prefeito da capital, Tavaré Vazques, é, do mesmo modo que outras experiências de transição aqui citadas, expressão de um desgaste do sistema tradicional de partidos do seu país. Impedido de chegar à presidência em 2001, pela união eleitoral dos outrora antagônicos Partidos Colorado e Branco, a Frente representou, em 2005, o ápice de um grande processo que modificou o mapa eleitoral uruguaio. ${ }^{12}$ De todo modo, aqui não se observou uma dinâmica de exclusão do jogo político e, para além da maior ou menor dureza da oposição, existe um marco institucional da disputa política. De fato, no discurso pronunciado na sua assunção presidencial, ele agradeceu não só o respaldo da cidadania e seus votantes, mas da oposição, que qualificou de leal.

Argentina e Peru representariam casos intermediários nos quais, apesar de não se negar a legitimidade dos atores no governo, a qualidade das instituições políticas mostra uma baixa intensidade e, adicionalmente, não parece existir uma oposição forte, com possibilidades de se constituir em opção de governo. Na Argentina, a coalizão de governo da

12 Triunfou na eleição presidencial de 31 de outubro e 2004, na qual se apresentava como candidato pela coalizão de esquerda Encontro Progressista - Frente Ampla Nova Maioria, ao obter a mayoría absoluta com 50,45\% dos votos válidos, transformando-se no primeiro presidente de esquerda e rompendo com a hegemonia bipartidaria do Partido nacional e do Partido Colorado, que dominaram a história política Uruguaia desde 1830.
Presidente Fernandez, continuidade da presidência de seu marido Nestor Kirchner, é mais homogênea, estruturada sobre o setor momentaneamente hegemônico do Partido Justicialista, incorporando desprendimentos dos partidos opositores, pelo que, somado à crise dos partidos políticos que estruturaram as identidades durante a segunda metade do século XX, não enfrenta uma oposição forte nem articulada. De todo os modos, nos últimos tempos, o perfil que o governo mostra encontrou a oposição de setores agregadores de empresários rurais, o que parece haver gerado uma espécie de expectativa para revitalizar a credibilidade de uma oposição atomizada, carente de lideranças claras e incapaz de instalar os temas na agenda. O conflito gerou um súbito e até pouco tempo atrás impensado protagonismo do Congresso Nacional, que poderia se constituir no âmbito de mediação de projetos antagônicos. O Peru parece ser também um caso atípico entre o pluralismo e um antagonismo que entorpece a geração de consensos de médio e longo prazo, se bem que a mesma eleição, ${ }^{13}$ pela segunda vez, de Alan Garcia como presidente tenha sido produto de um acordo partidário típico dos regimes eleitorais de dois turnos e e sistemas multipartidários.

A diferença mais significativa estaria na possibilidade ou não de propiciar condições para gerar cooperação. Observar-se-ia, assim, um pêndulo oscilante entre experiências centradas em projetos consensuados com protagonismo dos partidos políticos, como mediadores do jogo político, e aquelas em que a característica distintiva é a exclusão do outro como ator legítimo da arena político-partidária, deslocando o eixo dos partidos para os movimentos sociais. Nas dinâmicas políticas de Venezuela, Equador ${ }^{14}$ e Bolívia, a in-

${ }^{13}$ Alan Garcia foi eleito em segundo turno frente a Ollanta Humala. No primeiro turno, o Partido Aprista Peruano havia obtido $24,33 \%$ dos votos, apenas meio ponto mais que a candidata da Unidade Nacional Lourdes Flores, que havia obtido $23,80 \%$. O candidato vencedor fora da União pelo Peru, com $30.62 \%$.

${ }^{14}$ Parte da luta política entre governo e oposição se deslocou para o controle das ruas. Em outubro, o presidente Rafael Correa convocou um evento para celebrar seu primeiro ato de governo, contestada com uma outra de oposição, encabeçada pelo prefeito social-cristão de 
clinação movimentista parece mais marcada. Além da estrutura política de apoio ao presidente Chávez, o MVR (Movimnto Quinta República), as mobilizações de rua e o apelo ao respaldo popular como eixo da práxis política parece constituir uma constante tanto para o governo como para a oposição. A caracerística comum desse movimentismo na Bolívia e no Equador estaria dada pela importância do fator étnico, diferentementemente da Venezuela, onde se daria em função da adesão ou não ao socialismo bolivariano proposto pelo presidente Chávez.

A qualidade do jogo político se baseia na legitimidade dos atores, que devem se reconhecer como competidores válidos e legítimos, para além da defesa de projetos diversos ou antagônicos em termos ideológicos ou pragmáticos; na existência de mais de um partido de governo e, não menos importante, na possibilidade certa de que a oposição possa se constituir em alternância de governo. As características que a oposição assume constituem um fator central na configuração do sistema político-partidário. A existência de uma oposição mais ou menos leal parece ser parte de um eixo articulador da possibilidade de se estabelecerem políticas de Estado, mesmo nos casos em que a configuração de um modelo de sistemas padece de um respaldo pleno da qualidade institucional. Desse modo, a hegemonia do PRI, amparada na regra de designação do sucessor presidencial e na fraude eleitoral, apesar de não ter sido vencida pelo PRD (Partido da Revolução Democrática), que foi vítima de manipulação dos resultados eleitorais ${ }^{15}$ (com uma suspensão discricional e deliberada de

Guayaquil, Jaime Nebot, com a justificativa de defesa de sua cidade e de evitar a confrontação pela qual responsabilizava o presidente.

${ }^{15}$ As suspeitas de fraude do PRD ocorreram em duas oportunidades. Em 1988, Cuhautémoc Cárdenas, filho do líder histórico do PRI, Lázaro Cárdenas, sofreu uma derrota do candidato Carlos Salinas de Gortari com a qual subitamente se interrompeu o escrutínio definitivo, declarando-se vencedor o PRI, situação irregular para um amplo espectro de observadores internacionais. Nas eleições de julho de 2006, o candidato Andrés López Obrador foi vencido por Felipe Calderón, por uma pequena diferença de votos e, novamente, o Instituto Federal Electoral (IFE) rechaçou um uma contagem específica das urnas que apresentavam irregularidades. escrutínio incluída), encontrou no PAN um ator político mais confiável que se constituiu, primeiramente, em uma oposição leal e, logo depois, em um respaldo para um sistema que podia gerar uma alternância de governo em um segundo momento (Palma, 2004).

A mesma idéia de oposição leal, apesar das críticas que pode receber, representa a base do funcionamento do sistema político em seu papel mediador. Não se trata da impossibilidade de aderir a projetos alternativos. Significa que os atores aceitam as regras do jogo, compartilham um piso mínimo de compromisso com os valores de funcionamento, e, sem renunciar ao antagonismo típico de toda arena política baseada no conflito de projetos em luta, apela para a tolerância e para a importância de reconhecer o papel legítimo do oponente.

Podemos distinguir dois tipos de instituições do governo, aquelas que estão no cume do ordenamento hierárquico e as que integram o aparato administrativo do Estado. No nível institucional das organizações da administração pública, a bibliografia resgata que os sistemas mais estáveis e dinâmicos são aqueles em que as instituições não apresentam variações bruscas. A maior ou menor capacidade das instituições do aparato administrativo do Estado de se isolarem das crises do regime político no sentido amplo constitui vantagem comparativa para os diversos Estados. Nesse sentido, observam-se diversos caminhos na América Latina, o que se expressou numa capacidade díspar de levar a cabo políticas estáveis de médio e longo prazo. Santos (2008) resgata a continuidade de um pacote de políticas macro realizada nos últimos 15 anos, no Brasil, em que a chegada ao poder do Partido dos Trabalhadores (PT), longe de significar uma quebra, mostrou uma continuidade com a saudável agregação de uma ampliação das políticas sociais dirigidas às pessoas que se encontram na base da pirâmide distributiva. A estabilidade macro-econômica e a participação de atores políticos e empresariais seria a base de um jogo de resultado positivo propiciado pelo presidente Lula, no qual todos ganhariam. 
Outra variável do tipo política, chave para analisar as modalidades intervencionistas na América Latina, é a existência de núcleos de pacto os atores econômicos e políticos. A coordenação publico-privada aparece como eixo central da agenda neodesenvolvimentista. Em princípio, não é possível um modelo de desenvolvimento sem um empresariado forte (Boschi, 2006; Diniz, 2000; Diniz; Boschi, 2006; Sicsu, 2005). A existência de núcleos de pactos entre o setore público e o privado é fundamental em termos de vantagens institucionais comparativas. Também é o caso da existência de agências voltadas para o fomento e a implementação de políticas setoriais e industriais. Nesse ponto, é central o papel mediador das organizações de representação de interesses na mediação do conflito.

A implementação de modelos historicamente testados, que envolvem particularmente a coordenação por parte do Estado, é defendida por Chang (2002, 2003), que preconiza a necessidade de políticas industriais no sentido restrito e seletivo, capazes de promover, como foi no exitoso caso da Coréia, uma relação extremamente coordenada e afinada entre os conglomerados industriais e a burocracia do Estado. De todos os modos, a política industrial é apenas uma parte de um esforço intervencionista de maior alcance, que envolve as políticas de financiamento, o apoio à investigação e ao desenvolvimento, as relações horizontais, as políticas regionais e de integração regional e mundial. A definição mais restrita de política industrial enfatiza a dimensão setorial, o papel do Estado como coordenador, assim como a adoção de políticas seletivas.

A cooperação entre as elites econômicaso locais e a atuação coordenada de diferentes segmentos da burocracia é importante, no sentido de definir estratégias de desenvolvimento. Em última instância, deve-se ressaltar a importância de mecanismos institucionais para assegurar projetos de desenvolvimento de mais longo alcance. Nesse sentido não basta contar com projetos medianamente consensuados no interior dos diversos países, sendo necessário gerar as condições de possibilidade de implementação da agnda neodesenvolvimentista que analisamos detalhadamente a seguir.

Trata-se, definitivamente, de ressaltar a importância do Estado na constituição das diversas modalidades de capitalismo, dando conta das complementaridades que não são resolvidas no âmbito institucional localizado. As particularidades que são observadas entre os diferentes países estariam dadas, segundo nossa perspectiva de análise, pela matriz institucional.

\section{AAGENDA NEO-DESENVOLVIMENTISTA: vetores para um desenvolvimento inclusivo}

O desenvolvimento de um país representa um processo unívoco, difícil de ser reproduzido ou transplantado. Apesar disso, a observação analítica de casos exitosos de industrialização recente, que se expressaram em um caminho de desenvolvimento sustentável, permite dar conta de uma séire de fatores-chave que constituem uma matriz desenvolvimentista. Entre esses fatores, incluemse a estabilidade macro-econômica, a capacidade de gerar um sistema próprio de inovação, funcional para os interesses nacionais, a existência de sistemas de financiamento da produção e o emprego, modelos inclusivos de políticas sociais e sistemas de trabalho formais, a capacidade de regular os mercados, a existência de núcleos de ajuste entre o estado e o setor privado.

O neodesenvolvimentismo reconhece que as estratégias dos Estados-nação, em permanente e feroz competição, constituem o marco de possibilidade de uma estratégia de modernização e desenvolvimento sustentável. Por outro lado, adquire preeminência o conjunto macro institucional para gerar oportunidades para o investimento e o emprego. Nesse sentido, combina o valor da intervenção estatal com um respeito inegociável pelo valor da estabilidade monetária, em grande parte produto de um temor pelo retorno da espiral inflacionária que a região sofreu durante os anos oitenta.

A estabilidade macro-econômica se apre- 
senta como um eixo inegociável da nova agenda neodesenvolvimentista. Em princípio, as metas de crescimento, controle da inflação, aumento de superavit fiscal, controle dos interesses da dívida constituem um indicador de saúde da economia e, como tal, representam um conjunto de indicadores que são considerados pelos investidores. Adicionalmente, constituem um modo de blindar a economia frente às crises cíclicas, características do modo de produção capitalista e reduzir, em conseqüência, a vulnerabilidade externa. Nesse ponto, a situação é excepcional. Pela primeira vez, em quase 40 anos, os países da região transitam por um ciclo de crescimento e equilíbrio fiscal. O superavit fiscal expressa a maior capacidade de um país levar a cabo investimentos próprios, sem o controle de fontes externas de financiamento, e adquire maior importância em virtude dos elevados níveis de endividamento dos países sul-americanos. Por outro lado, certos mecanismos dos sistemas de financiamento, com a fixação de taxas diferenciais em função de uma série de variáveis macro do país, atuam como um fator disciplinador de possíveis distorções. A estabilidade fiscal e macro-econômica passa a ter um papel-chave. ${ }^{16}$

O crescimento, que se apresenta como imperativo para o desenvolvimento, representa um desafio para os países da região, para além de certas exceções mostrarem baixas taxas de crescimento, situando-se abaixo das taxas que a maior parte dos países do mundo apresentam. Inclusive a média de crescimento anual para o período 2000-2006 na região $(3,1 \%)$ é uma das menores, apenas maior que a média dos países centrais (2,3\%), estando abaixo do crescimento da África Sub-Sahariana (4,7\%) Ásia Pacífico (8,6\%), ásia Central (5,7\%), Oriente Médio e África do Norte (4,1\%) e Ásia do Sul (6,9\%); menor inclusive, que a média das eco-

${ }^{16} \mathrm{O}$ valor da estabilidade fiscal e macroeconômica foi questionada, nos últimos anos, devido ao problema crescente da inflação, especialmente de alimentos. Frente ao tema, observam-se duas grandes tendências nos países latino-americanos: o controle de preços e comércio exterior de certos alimentos básicos (arroz, carne, grãos) ou o controle das taxas lucro, com o objetivo de ajustar os possíveis efeitos indesesáveis do "reaquecimento" das economias. nomias de investimento médio (5,6\%).

Os sistemas de financiamento do desenvolvimento e, especialmente, aqueles que se centram em diversificar a produção e privilegiar os mecanismos de inovação, constituem uma parte axial das novas estratégias desenvolvimentistas. A posição relativa de um país ou região no mercado internacional se encontra, atualmente, cada vez mais relacionada com a capacidade de gerar e ampliar o uso da tecnologia, entendida como um fator-chave para se obterem incrementos de competitividade que assegurem uma melhor presença nos mercados mundiais. Uma olhada na história ensina que os processos de desenvolvimento se assentaram na massificação da difusão da tecnologia, como garantia da irreversibilidade do progresso social. Esse foi o caminho dos modelos clássicos de desenvolvimento gerados pela revolução industrial do século XX (Estados Unidos, Alemanha e Japão) e dos NIC asiáticos da segunda metade do século XX (os dragões Signapura, Coréia e os posteriores Tigres, Malásia, Tailândia e Vietnam), experiências que fizeram especiais esforços para potencializar a capacidade de geração e captação de tecnologia por parte da população em seu conjunto. Diferentemente da América Latina, que teve sua fase de crescimento assentada na exportação de matérias primas e de indústrias de matrizes estrangeiras, esses países investiram amplas somas de recursos em investigação e desenvolvimento, sistemas universitários e renovação tecnológica e de suas matrizes do aparato produtivo.

A crescente importância do domínio da técnica, numa economia do conhecimento, pode ser medida por meio de vários indicadores, sendo o mais usual o investimento destinado à investigação e ao desenvolvimento, tanto em termos absolutos como em taxa sobre o produto interno. $\mathrm{Na}$ década que vai de 1992 a 2001, o investimento em pesquisa e desenvolvimento quase duplicou em todo o mundo: passou de algo mais de 400.000 milhões a mais de 700.000 de dólares, um aumento de $17 \%$. O crescimento, nos anos transcorridos deste século, é ainda maior. Desse montante, a região da América Latina e do Caribe corresponde a 
apenas 1,6\%, uma soma que só supera o investimento da Oceania , e que os países do bloco da América do Norte superam em 25 vezes. A Ásia e a Europa investiram aproximadamente 18 vezes mais. Nessa corrida pelo conhecimento, os países da América Latina se encontram, em geral, atrasados, mas as diferenças são notórias.

No conjunto dos países latino-americanos, somente o Brasil, desde o ano 2000, alcança anualmente a meta de $1 \%$ do investimento do PIB em pesquisa e desenvolvimento, considerado uma espécie de fronteira entre os países que começam a se desenvolver e as economias mais débeis. É, assim, o país da região que se destaca sobre a pobre média geral da América Latina, que se coloca em torno de 0,6\%. A Argentina apresenta uma taxa ainda menor, de $0,45 \%$ histórica e que, pelos vaie-vem próprios de sua dinâmica econômica, desceu a níveis apenas superiores ao 0,30\%, a metade do investimento chileno. Esses dados são modestos, inclusive em comparação com os paíse de baixo desenvolvimento, como os do Sul da África (0,8\%), Nepal (0,7\%) e Uganda (0,8\%).

A questão social representa um eixo constitutivo dos novos modelos intervencionistas. A agenda social ocupa um plano relevante no modelo neodesenvolvimentista. Os países da América Latina mostraram capacidade de combinar crescimento e igualdade. Em 1970, a América Latina, em seu conjunto, cresceu a uma taxa média de $3 \%$, apesar da porcentagem e do número de pessoas pobres se manterem constantes. Atualmente, quase 40\% dos latino-americanos são pobres (cerca de 210 milhões de pessoas) e 15\% indigentes.

Um dos aspectos centrais da agenda pósneoliberal, em termos de desafios do desenvolvimento, na atual etapa de globalização refere-se não apenas aos aspectos econômicos, mas, especialmente, à sua dimensão social, basicamente à capacidade de estender os benefícios do desenvolvimento a toda a sociedade. Essa preocupação com a inclusão social se encontra tanto no debate acadêmico como nas experiências neodesenvolvimentistas.

O desenvolvimento deve chegar a todas as camadas sociais. Nesse sentido, o papel das políticas sociais é essencial. Um núcleo de políticas de transferência de renda, de investimento em serviços sociais básicos, de capacitação para o emprego, com uma lógica de inserção social que escape ao mero assistencialismo, constitui uma necessidade das atuais administrações. Para além de certas iniciativas privadas amparadas pela retórica da responsabilidade social, somente o Estado pode atuar como protetor dos setores mais desprotegidos das durezas do mercado.

A discussão teórica reconhece que, para ter êxito, uma experiência de desenvolvimento deve não só aumentar o produto, mas expandi-lo para a sociedade, melhorando o nível de vida. O livro de Evelyn Huber (2002), sobre modelos de capitalismo, aborda estudos que rompem com a visão estereotipada acerca da existência de um modelo liberal genérico, por oposição a uma versão igualmente única de intervencionismo estatal, e reintroduz a dimensão social como o cerne das políticas de desenvolvimento. Segundo a autora, políticas sociais e de crescimento econômico se reforçam mutuamente e somente através de políticas econômicas que contemplem o aspecto social a América Latina poderá instaurar um novo ciclo de desenvolvimento. Por outro lado, deve-se destacar que foi a ênfase na dimensão social e as propostas de políticas de transferência de renda e de integração social de amplos segmentos marginais os fatores que explicam o giro ideológico do eleitorado latino-americano, que optou por governos progressistas. A nova agenda ficou definida, desse modo, por uma preocupação com o retorno do crescimento, num modelo em que as políticas sociais assumem um lugar estratégico, mas ainda levando em conta o compromisso com a manutenção da estabilidade, num contexto de crescente competência, derivado da globalização financeira e comercial, que limitam especialmente os graus de liberdade para a implementação de políticas orientadas para o crescimento.

Também, nesse caso, uma questão de ordem prática alimenta a discussão e se relaciona com a possibilidade de aprender com os casos 
exitosos de desenvolvimento, em que a totalidade ou a maioria da população participou do processo de transformação, crescimento e distribuição de seus frutos. Esses países não registraram fraturas abissais na sociedade fundadas em causas étnicas ou religiosas, nem em diferenças extremas na distribuição da riqueza e o investimento. ${ }^{17}$

A ampliação dos níveis de consumo, especialmente daqueles historicamente postergados, apresenta-se como uma demanda de governantes e governados. Nesse sentido, o crescimento demográfico e o tamanho populacional dos países, frequentemente apresentados como obstáculos para o desenvolvimento, tornaram-se característica positiva. Pode-se dizer que os países que contam com uma população importante, e que sejam exitosos no desafio de incluir toda a sociedade no consumo, com o respeito de seus direitos sociais e econômicos, guadam vantagens em comparação a países pequenos. Os denominados BRIC, sigla que representa Brasil, Rússia, Índia e China, se encontram entre os países mais povoados do mundo e representam, em conjunto, quase $45 \%$ da população mundial. O desafio passaria, assim, pela reversão do processo piramidal, em que só uma parte da população conta com direitos econômicos e sociais.

Nesse caminho, os países da região têm um largo caminho a percorrer. Os indicadores de pobreza, indigência e desigualdade revelam que, na América Latina, a mais desigual do mundo, a distância entre os extremos persiste. Apesar da escandalosa magnitude da desigualdade e da indigência, certos esforços das atuais administrações buscam essa tendência, por diferentes caminhos, desde as políticas de concessões, como o Bolsa Família no Brasil, o Plano Chefes de Família Desocupados, ou o Plano Famílias para a Inclusão Social, na Argentina, até as missões sociais na Venezuela.

\footnotetext{
${ }^{17}$ Em Taiwán, por exemplo, ao mesmo tempo em que se mudou sua matriz produtiva (em 1960 a agricultura representava $30 \%$ do PIB, com um investimento médio de 200 dólares estadunidenses e, em 2007, caiu para $3 \%$, com um investimento de 12.500).
}

\section{EPÍLOGO}

Ao longo deste trabalho, afirmamos que se observa, na América Latina, um retorno a processos que denominamos de neodesenvolvimento, constitutivos de uma dimensão substancial dos governos latino-americanos, que apresentam como característica comum um retorno do intervencionismo estatal, diferenciando-se, no conteúdo, dos projetos nacionais. Particularmente, analisamos o papel-chave do sistema político na geração de condições próprias para assegurar dinâmicas de desenvolvimento sustentável. A primazia da política, em momentos em que se encontra em formação a agenda pós-neoliberal, é central. Além de fatores exógenos que se traduzem em fortes condicionantes para países periféricos, os fatores endógenos explicam as fortes variações que se apresentam entre os países. De fato, cremos que nao há uma modalidade fixa de Estado capitalista, nem algum tipo de determinismo que condene os Estados latino-americanos ao atraso e à marginalidade de suas sociedades.

Em segundo lugar, podemos afirmar que esse neodesenvolvimentismo ou neointervencionismo representa um modelo híbrido de coordenação econômica efetuada também a partir do mercado. Isso significa que não existe uma volta ao Estado produtivo, mas, apenas, um maior grau de coordenação estatal da esfera econômica, com maior espaço para atividades de regulação e controle. Apesar de existirem novos esquemas de intervenção do Estado na órbita produtiva, essa atividade adquire um papel estratégico, mas não proeminente.

O impacto dos processos prévios permite aos países uma atitude diferenciada frente aos fatores que consideramos parte constitutiva esencial de uma nova agenda de desenvolvimento e que implica uma sinergia entre Estado e setor privadopúblico não estatal; a criação de um setor privado forte e competitivo, em paralelo ao desenvolvimento de um setor público eficiente, que possa corrigir erros e pontos débeis, descentralizar suas atividades e dirigir seus esforços para potencializar re- 
cursos e capacidades. Não existe um modelo único. As trajetórias diferenciais dos países que assentam seu projeto desenvolvimentista em um maior grau de coordenação entre Estado e mercado, em contraposição a experiências críticas do mercado, respaldam o argumento relativo ao papel do Estado de outorgar uma caractrística diferencial aos projetos de desenvolvimento. A orientação das administrações pós-neoliberais mostra que não exite, na América Latina, um só caminho para o desenvolvimento. De fato, as variáveis e a agenda neodesenvolvimentista que foram apresentadas aqui, na seção anterior, que constituem a matriz constitutiva de novos modelos de desenvolvimento, apresentam-se, em cada Estado-nação, de modo particular. As trajetórias prévias constituem o ponto de partida que prenuncia diferentes perspectivas de avanço na implementação de reformas econômicas e sociais.

Diferentes trajetórias (aquelas que marcam a história recente do período desenvolvimentista) constituem a base a partir da qual opera um conjunto bastante similar de intervenções (as reformas setoriais no marco do ajuste estrutural), delimitando um campo para a atuação de novos governos, cujos instrumentos e margens de ação dependerão de um conjunto de características institucionaise de contexto que pautam a governabilidade e, em última instância, a natureza das políticas econômicas.

As vantagens institucionais comparativas não formam um núcleo estático e não apenas foram variando ao longo do tempo, mas uma característica que, em um momento, era entendida como negativa pode passar a ser vista como um eixo de desnvolvimento. Isso se relaciona, por um lado, com a dimensão temporal que assumimos aqui. Por mais que seja desejável que os países latinoamericanos transitem pela senda do desenvolvimento o mais rápido possível, o momento em que os diferentes países empreendem o catch up é particular. Que os países da região, vistos em condições de dar o salto nos anos setenta, não o tenham dado não significa que esses salto não se possa dar.
A reversão da deterioração dos termos de intercâmbio (em parte pela ampliação das fronteiras agrícolas, o alto custo das comodities e a alta produtividade do setor primário) juntamente com a constituição de um mundo multipolar ou, num olhar radical, de ausência de polaridade, como estariam indicando a crise dos Estados Unidos da América e o vazio deixado pela hegemonia que exercia, constituem uma oportunidade propícia do ponto de vista da efetiva possibilidade de os países da América Latina ampliarem suas capacidades para o desenvolvimento.

Nossa defesa do Estado como o único capaz de reverter o processo de subdesenvolvimento das plenas potencialidades dos países da região implica uma reivindicação das instituições, como motor de desenvolvimento, como nexo de criação de acordos e compromissos em que os diversos atores sociais (trabalhadores, empresários, cientistas, burocratas e decisores de governo) aportem sua experiência de modo incremental. Definitivamente, as instituições devem atuar como facilitadoras. Muito mais do que as críticas que se fazem à abordagem institucional, elas representam, na nossa visão, a expressão de demandas que permitem canalizar o jogo político. Porque uma estratégia de desenvolvimento autônomo exitoso parece consistir precisamente, nisso: em lograr recuperar, para o espaço político, níveis crescentes de autonomia de decisão. Estabelecer que existe uma relação estrita entre instituições de governo e instituições econômicas não significa subsumir a política ao domínio da economia, senão, pelo contrário, reclamar a necessidade de cada sociedade de estabelecer acordos mínimos que permitam o desenvolvimento e o bem-estar.

A hora atual - com a reversão da deterioração dos termos de intercâmbio, com a demanda crescente de produtos que a região produz naturalmente, com a ampliação dos mercados asiáticos que parecem anunciar a manutenção dessa demanda por um tempo relativamente longo constitui uma excelente oportunidade para que os países, ancorados em seus interesses nacionais, a partir de uma perspectiva local e regional, 
possam dar um salto de competitividade e ampliar os benefícios do crescimento para a sociedade em seu conjunto.

(Recebido para publicação em maio de 2008)

(Aceito em julho de 2008)

\section{REFERÊNCIAS}

AMABLE, B. The diversity of modern capitalism. Oxford: Oxford University Press. 2003.

BECKER, U. Open systemness and contested reference frames and change: a reformulation of the varieties of capitalism theory. Socio-Economic Review, Oxford, v. 5, n. 2, 2007.

BOSCHI, R. Business, economic reform and the state: development perspectives in Brazil. In: Congreso de la Asociación Internacional de Ciencia Política, Sesión Especial, 23 S01 289 Reforming Policies. 2006. Mímeo.

BOYER, R. How and why capitalisms differ. Economy and Society, Washington, Sage, v. 34, n. 4, p.509-557, 2005.

BRESSER PEREIRA, L.C. O Novo Desenvolvimentismo e a ortodoxia convencional. São Paulo em Perspectiva, São Paulo, Fundação Seade, v. 20, n. 1, jan./mar., 2006

DINIZ, E. Globalizacao, reformas económica e elites empresariais - Brasil anos 90. Rio de Janeiro: FGV, 2000.

HAGGARD, S. Pathways from the Periphery. Ithaca: Cornell University Press, 1990.

. Institutions and growth in East Asia. Studies in Comparative International Development, [S.l.], v. 38, n.4, p.53-81, 2004

HAGOPIAN, F.; SCOTT, Mainwaring (Ed.) The third wave of democratization in Latin America. Advances and setbacks .New York: Cambridge University Press .2005.

HALL, P.; SOSKICE, D. Varieties of capitalism: the institutional foundations of comparative advantage. Oxford/New York: Oxford University Press, 2001.

The Evolution of varieties of capitalism in Europe. In: HANKÉ, Bob; RHODES, Martim; THACHER, Mark (Ed.) Beyond varieties of capitalism: conflict, contradictions, and complementarities in the European economy. Oxford: Oxford University Press, 2007. Disponível em: www.amazon.com/gp/reader/0199206481/ref=sib_dp_pt/ 103-0947572-6409418\# reader-link

HAUSMAN, Ricardo; RODRIK, Dani. Economic development as self discovery, Cambridge: JFK School of Government, 2003.

HUBER, Evelyn Models of capitalism: lessons for Latin America. Pennsylvania: University Park, 2002.

; NIELSEN, F.; PRIBBLE, J.; STEPHENS, J. Politics and inequality in Latin America and the Caribbean. American Sociological Review. Washington, v. 71, n. 6, 2006

MENZ, George. Re-regulating the single market: national varieties of capitalism and their responses to europeanization. Journal of European Public Policy, [S.l.] v. 10 , n. 4.2003.

NORTH, Douglas. Institutions, institutional change and economic performance. Cambridge: Cambridge University Press, 1990.
Economic performance through time. In: BRINTON M. C.; NEE, V. The new institutionalism in sociology. Stanford: Stanford University Press, 1998.

Understanding the process of economic change. Princeton: University Press, Princeton, 2005.

PALMA, Esperanza. Las bases políticas de la alternancia en México: un estudio del PAN y el PRD durante la democratización. México: UAM, 2004.

PIERSON, P. Politics in time: history, institutions and social analysis. Princeton: Princeton University Press, 2004.

RODRIK, Dani. The global governance of trade: as if development really mattered. Presentación ante el (PNUD). Programa de las Naciones Unidas para el Desarrollo. New York: (PNUD), 2001. Disponível em: http://ksghome. harvard.edu/ drodrik/undptrade.pdf

Rethinking growth policies in the developing world. Torino-Italy: Luca d'Agliano Lecture in Development Economics, 2004.

SCHAMIS, Hector E. Re-forming the state: the politics of privatization in Latin America and Europe. Ann Arbor: The University of Michigan Press, 2002.

SCHNEIDER, Ben. Comparing capitalisms: liberal, coordinated, Network, and Hierarchical Varieties, [S.l.]: 2008. Mimeo.

Hierarchical market economies and varieties of capitalism in Latin America. [S.l.]: 2007. Mimeo.

Varieties of semi-articulated capitalism in Latin America. Paper presentado al encuentro APSA, Chicago: 2004. Mimeo.

Business politics and the state in twentieth century Latin America. Cambridge: Cambridge University Press, 2004a.

SIKKIN, Kathryn. Las capacidades y la autonomía del Estado en Brasil y la Argentina: un enfoque neoinstitucionalista. Desarrollo Económico, Buenos Aires, v. 32, n. 128 ene./mar., 1983.

SOSKICE, D. Divergent production regimes: coordinated and Uncoordinated Market Economies in the 1980's and 1990'. In: STIGLITZ, Joseph H. Towards a new paradigm for development: strategies, policies and processes. Genova: Prebisch Lecture; UNCTAD, 1998.

STOKES, Susan. Mandates and democracy: neoliberalism by surprise in Latin America. Cambridge: University Press, Cambridge, 2001. 


\section{STATE INTERVENTIONISM AND DEVELOPMENT POLICIES IN LATIN AMERICA}

\author{
Renato Boschi \\ Flávio Gaitán
}

This work analyzes the dynamics of the LatinAmerican countries in the last decade, which distinctive characteristic is the weakness of the neoclassical hegemony and a retaking of state intervention trajectories in the economy. The analysis is centered in the constituent vectors of a neodevelopmentist calendar and in the role that the State should carry out in the retaking of growth and of sustainable development. In focus are the roles that the political regime and government institutions accomplish in the economical process, with the suggestion that there would be no possibility of growth and development without a strong State. Different trajectories constitute the base from which a similar group of interventions operate delimiting a field for the attraction of new governments, which instruments and action margins will depend on a group of institutional characteristics and of context that rule governability and, in last analysis, the nature of the economical policies.

Keywords: development, Latin America, political institutions, State, market.

\section{L'INTERVENTIONISME D'ETAT ET LES POLITIQUES DE DEVELOPPEMENT EM AMERIQUE LATINE}

\author{
Renato Boschi \\ Flávio Gaitán
}

Ce travail analyse les dynamiques des pays latinoaméricains au cours de la dernière décennie dont la caractéristique spécifique est l'affaiblissement de l'hégémonie néo classique ainsi que la reprise de trajectoires d'intervention de l'état dans l'économie. Lanalyse se concentre sur les vecteurs constitutifs de compromis néo développementistes et sur le rôle que l'Etat doit jouer pour la reprise de la croissance et du développement soutenable. On y focalise le rôle que le régime politique et les institutions du gouvernement assument au niveau du processus économique. Il semblerait ne pas y avoir de croissance possible ni de développement sans un Etat fort. Diverses trajectoires constituent la base à partir de laquelle un ensemble similaire d'interventions opère en délimitant un champ d'action capable d'attirer de nouveaux gouvernements dont les instruments et les marges de manoeuvre dépendront d'un ensemble de caractéristiques institutionnelles et d'un contexte capables d'orienter la gouvernabilité et, en dernière analyse, la nature des politiques économiques.

Mots-CLÉs: développement, Amérique Latine, institutions politiques, Etat, marché. 